\title{
Lessons from Masters World Records: Lack of Gender Differences In Aging Muscle Decay Rates
}

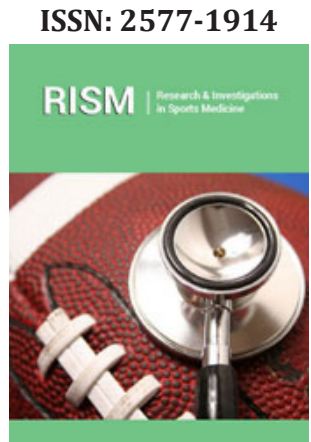

*Corresponding author: Giovanna $\mathrm{Al}$ bertin, Department of Neuroscience, Section of Human Anatomy, University of Padova, Via Gabelli 65, 35128, Padova, Italy

Submission: 䁈 December 18, 2019

Published: 㭗January 09, 2020

Volume 6 - Issue 1

How to cite this article: Guidolin D, Gava P, Ravara B, Kern H, Amber Pond L, et al. Lessons from Masters World Records: Lack of Gender Differences In Aging Muscle Decay Rates. Res Inves Sports Med. 5(5). RISM.000626.2020.

DOI: $10.31031 /$ RISM.2020.06.000626

Copyright@ Giovanna Albertin, This article is distributed under the terms of the Creative Commons Attribution 4.0 International License, which permits unrestricted use and redistribution provided that the original author and source are credited.

\author{
Guidolin $\mathrm{D}^{1}$, Gava $\mathrm{P}^{2}$, Ravara $\mathrm{B}^{2,3}$, Kern $\mathrm{H}^{4}$, Amber Pond $\mathrm{L}^{5}$ and Albertin $\mathrm{G}^{1,6 *}$ \\ ${ }^{1}$ Department of Neuroscience, University of Padova, Italy \\ ${ }^{2}$ A\&C M-C Foundation for Translational Myology, Italy \\ ${ }^{3}$ Department of Biomedical Science, University of Padova, Italy \\ ${ }^{4}$ Ludwig Boltzmann Institute for Rehabilitation Research, Austria \\ ${ }^{5}$ Department of Anatomy, Southern Illinois University School of Medicine, USA \\ ${ }^{6}$ Human Movement Sciences, University of Padova, Italy
}

\begin{abstract}
The physiology and physiopathology of muscle aging differ between female sand males. Here, our aim is to investigate gender differences in the rate of the age-related decay of skeletal muscle performance using a complete series of female and male normalized master's world records. Masters athletes compete in age groups of five-year divisions and range from 35 to 100 years of age. The world records are lists of up to 16 data points that, after normalization, can be interpolated with polynomial trend-lines with a high R2. Gender comparisons were performed for 19 Track and Field specialties using weighted regression analyses. As expected, the aging decline began at 35 years for both the women and men. Despite differences in the 19 Track and Field Masters world records for female and male athletes in the same age groups, in comparing the normalized female and male Masters athlete world records, the rates of aging performance decay were very similar if not identical. This lack of gender difference is a unique exception to the general rule of gender differences in sports activities, suggesting that neuro-hormonal mechanisms poorly influence the rate of aging muscle power decay. We then discuss the hypothesis that age-induced decline is related to fundamental cellular mechanisms, perhaps those that control energy metabolism. The limitations and implications of our hypothesis are discussed as well.
\end{abstract}

Keywords: Masters world records; Aging muscle; Rate of performance decay; Gender differences

Abbrevaitions: CoM: Center of Mass; d.f: Degrees of Freedom; IAAF: International Association of Athletics Federation; VO2max: Maximal Oxygen Consumption

\section{Introduction}

Life expectancy is longer for women than for men [1] despite the fact that females have consistently weaker muscle strength when compared with coetaneous young, old, and oldest males [2-4]. Thus, it has been firmly established that females and males do not age in the same manner. The world records of Senior and Masters athletes in Track and Field competitions provide strong evidence of this fact in the differences between the recorded performances of the male and female athletes [5]. Masters athletes compete in age groups divided by five-year periods (from 35-39, 40-44, and so on until the age of 110 years).

In general agreement with previous studies [6-13], Gava et al. [5] reported a decline in athletic performance with age, developing interesting conclusions when analyzing a decline in the performances of male Masters athletes in running, jumping, and throwing events revealed through comparisons with the world records: 1 . Most track and field events showed a linear decline up to 70 years; 2 . The annual rate of power decline for all events, identified through a simplified synthesis, was $1.25 \%$ per year; 3 . The events that involve mostly upper limbs (throwing) showed an initial higher rate of decline (1.4\% per year) compared to those for which the lower limbs are mostly involved (long jump 1.1\% and track events $0.6 \%$ per year) [5]. All these conclusions were drawn by comparing the declining trends of the male Masters athletes after transforming the measured athletic performance into a parameter 
proportional to the power developed by the athlete in carrying out the athletic gesture. Such a parameter is a dimensionless number ranging from the maximum value of 1 (for the absolute world record, that is, those of the Senior Athletes) to decreasing values corresponding to the decreasing performance of the Masters athletes. The many confounding factors found in clinical studies on age-related performance usually decay, so the different lengths of clinical longitudinal studies [11,14-16] or the use of different modalities to measure strength, power, and resistance to fatigue [17] were avoided. The results of this normalization were rows of up to 16 performance parameters conveniently interpolated with polynomial trend-lines that allow for the direct comparison of the performance of very different athletic gestures. Using normalized data, the main conclusion of the Gava et al. [5] study was that the performance decline noted in the different Track and Field events was actually very similar across all events and that this variability was more related to the methodology used for the normalization of the records of the different athletic specialties. In a second study, these analyses were extended to include comparisons of male and female Masters athletes in 19 Track and Field competitions, providing physical [18] and statistical evidence [19] that there are only very minor gender differences in the age-related performance decay between female and male Masters athletes. Since our initial conclusions, according to the criticisms of external evaluators, were based on a naïve statistical approach, we will here report the results of more robust statistics (i.e., weighted regression analysis) [20].

\section{Materials and Methods}

\section{World records database}

First, our approach required a database with all the world records from the main disciplines of athletics: 11 track, 4 throwing, and 4 jumping events. These collated records contained data from all the Masters athlete categories, both female and male (19 categories per gender). Data from the world records of Senior athletes and on all the Masters athletes was collected from the official archives of different world athletic associations: IAAF (International Association of Athletics Federation [http://www.iaaf.org/]) [21] for the absolute world records of Senior athletes and the world Masters athletics (http://www.world-masters-athletics.org/) [22] for the world records of Masters athletes. All data used in this study was public data collected from events officially recognized by the World Federation of Athletics. They are the official records valid as of May 2013, but similar results could be obtained for previous and successive years.

\section{All athletic performances are "power performances"}

The work to displace the body of the athlete from the start to the finish line divided by the time spent is directly proportional to the power developed (the less time, the more power). Meanwhile, the distance reached by the piece of equipment in throwing is directly proportional to the kinetic energy transmitted to the equipment by the athletic action, again proportional to the physical power developed by the athlete.

\section{Normalization procedure}

After collection of the database, the data from each event in the Masters world records were "normalized" using each relevant absolute world record, taken as the reference value of 1 . Specifically, the data from the Masters world records, which increased generally with age (such as time for the running events), was normalized by dividing the absolute record by the Masters record. On the other hand, the data on the events, which decreased with age (such as the height for the high jumping events and distance for the throwing and long jumping events) were normalized in an opposite manner: the Masters record was divided by the absolute record. Consequently, the normalized records of each event were sets of dimensionless values that decreased with age, from 1 (normalized value of the absolute record) to 0 for a null value. With such a procedure, the performances always decreased with age, in line with the usual idea of decline, regardless of the fact that the measured performance values increased (running) or decreased (throwing and jumping) with age. This was to allow for a consistent form of measurement and graphical representations across the different events, which reflected the fact that increased age was associated with a decrease in performance. We will later discuss the limitations imposed on the normalization of the other variables needed to compensate for the other aspects of Masters athletes competing at increasing ages (see two-step normalizations).

\section{Statistical analyses}

For each discipline, a weighted regression analysis was used to estimate the course of the performance as a function of age. The slopes of the best fitting lines (representing the rate of change in performance) obtained from both the males and females were then compared using a Student's t-test [23]. As an index of overall performance at each age point, the mean value of the normalized records was considered. Each of these points, however, did not provide equally precise information on the deterministic part of the total process variation, since the number of disciplines with an available world record decreased with the increasing age of the athletes. To account for this aspect, a weighted regression procedure was used to characterize the trend exhibited by the overall performance score as a function of age [24]. This was done by associating each point with a weight corresponding to the number of normalized data contributing to its value in order to give each data point a proper amount of influence over the parameter estimates. The line slopes estimated for both the males and females were then compared using a student's t-test. For the statistical analysis, the SPSS 13.0 software was used, and $\mathrm{p}<0.05$ was used to determine statistical significance.

\section{Result and Discussion}

The normalized parameters of our study were derived from the world records of Masters athletes (male and female) for 19 athletic disciplines. 


\section{Why two-step normalization?}

In the case of throwing events, performances needed to be further normalized by taking into account the decreasing weight of the implements with the increasing age of the Masters athletes. For the jumping events, the power developed by the athletes as associated with the displacement of the Center of Mass (CoM) of their own body, which is essentially equal to the jumping length for horizontal jumping events (e.g., Long Jump and Triple Jump), but is not proportional to the height of the cross bar in vertical jumping events (e.g., High Jump and Pole Vault). The height of the vertical jumps was unquestionably mainly linked to the speed of the athlete's CoM at the time of detachment. Such speed, according to Newton's second law of motion, depends directly on the impulse imparted on the athlete's mass at take-off. The impulse, in turn, depends on the athlete's ability to accelerate his CoM, a capacity that is directly linked to the power developed in the athletic gesture. For this reason (in spite of controversial objections raised by some authors; [25-27]), we treated the lifting of the athlete's center of gravity in the jump as directly connected to the power developed by the athlete in the execution of the jump $[25,28]$. Indeed, when performing vertical jumps, the athlete has to raise his own CoM from a starting level of about $110-120 \mathrm{~cm}$ from the ground at the take-off point to $10-20 \mathrm{~cm}$ above the crossbar. Thus, vertical jumping performances require a two-step normalization process in order to obtain a normalized dimensionless parameter proportional to the power developed during the performance. Despite some approximations, this method allowed for a conceptually correct "normalization" of vertical jumps.

On the other hand, despite these approximations, all slopes had an R2 higher than 0.90, suggesting a continuous process of performance decay with age that occurring in both male and female athletes throughout life from at least the age of 35 (when the data was first gathered) [5].

\section{Rates of performance decline in Masters athletes: No statistical gender difference}

Figure 1 shows, for each considered discipline, the slopes of the best fit lines of the normalized records as a function of age for both males and females. The values are represented together with their estimated standard errors. Asterisks indicate disciplines for which a statistically significant difference was found between male and female athletes in terms of the rate of performance change. We were unsurprised that these were jumping and throwing events (see above). Figure 2 shows the weighted linear regression of the overall performance score (mean value across the disciplines of the normalized record data) as a function of age. The obtained line slopes for the males (black dots, solid line) and females (white dots, dashed line) are shown together with their standard errors and degrees of freedom (d.f.). No statistically significant differences were detected when applying the student's t-test $(p=0.171)$.

\section{Rates of performance decline in master's athletes: Implications and conclusions}

The results of our analysis revealed some indisputable elements:

1. Despite the differences in the absolute performance of female and male skeletal muscles (15\% lower in females) [2-4], the trend of performance decline with age was similar, if not identical, for the two genders (Figures 1 \& 2).

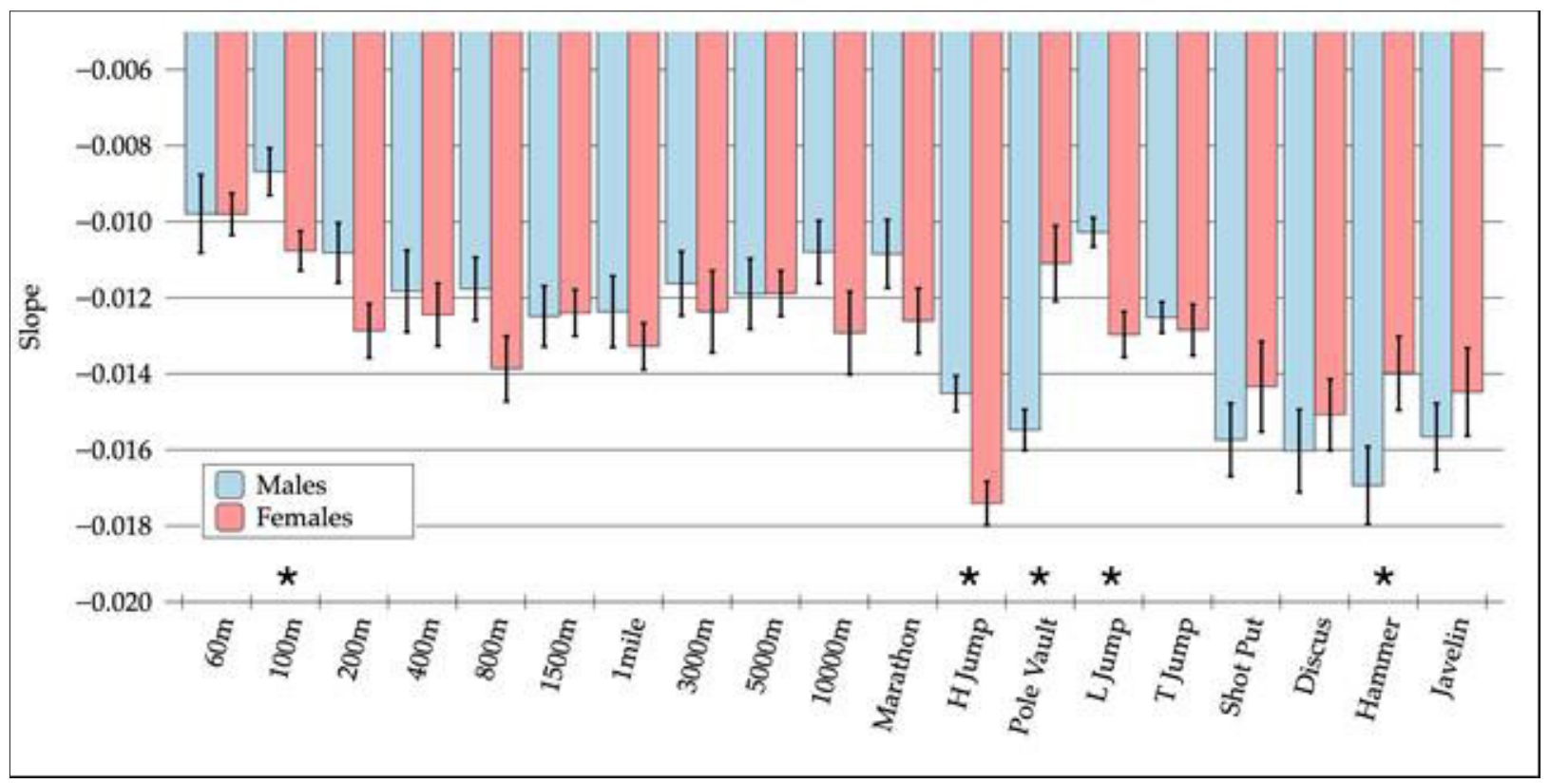

Figure 1: For each considered discipline, the slopes of the best fit lines of the normalized records as a function of age for both males and females are shown. Values are represented together with their estimated standard errors. Asterisks indicate disciplines in which a statistically significant difference was found between male and female athletes in terms of the rate of performance change. 


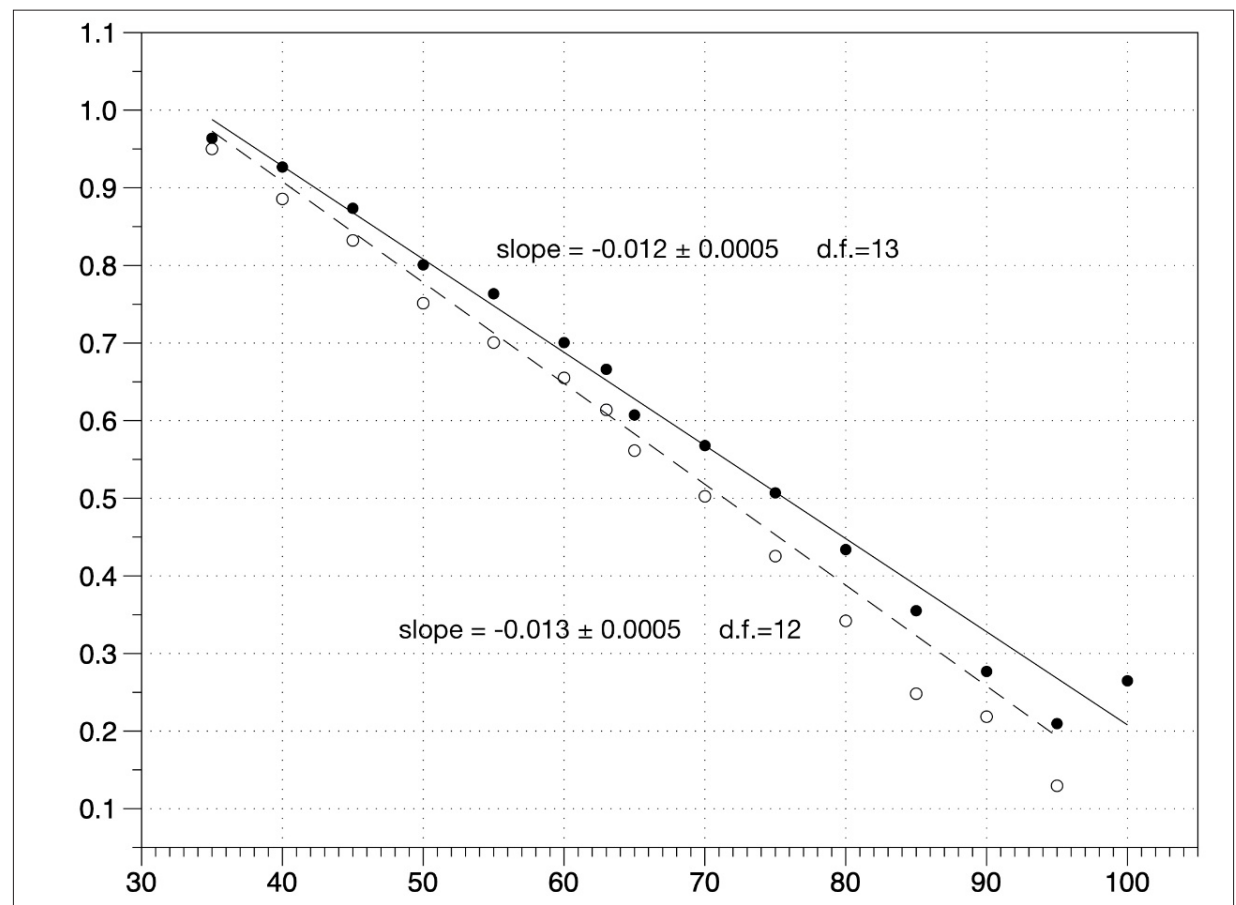

Figure 2: Weighted linear regression of the overall score of performance (mean value across the disciplines of the normalized record data) as a function of age. The obtained line slopes for both the males (black dots, solid line) and females (white dots, dashed line) are shown together with their standard errors and degrees of freedom (d.f.). No statistically significant difference was detected when applying the Student's t-test $(\mathrm{p}=0.171)$.

2. The weighted regression analyses of the male vs female dimensionless parametric data did not reveal any unexpected peculiarities, which is agreement with previous analyses that used different approaches [6,8,10,11,12,24,29,30], with exceptions related to 2-step normalization events (see above).

The present data suggested the irrelevance of the impact of well-known gender differences in neuro-humoral physiologic mechanisms on the rate of skeletal muscle decay with age. Thus, we hypothesize that aging decline is related to fundamental cellular mechanisms, specifically those that control energy metabolism [3134]. Also observed were the roles of epigenetic mechanisms (i.e., of acquired mutations in gene expression that may regulate Masters genes roles in energy metabolism) [35-40]. Indeed, among the main physiological determinants of endurance performance, maximal oxygen consumption [VO2max) appeared to be the parameter most altered by age [29-41].

Moreover, these same mechanisms are present as pathogenic factors in many disorders that present behaviors described as "early or premature aging" [42-44]. This opens new perspectives on anti-aging countermeasures based on volitional exercise $[12,13]$ or other physical rehabilitation approaches [45-55]. The reasons behind the observed minor gender inequalities in aging decline need to be further clarified, despite an immense amount of literature on gender differences in aging [1-5,12-14,29-33,56,57]. On the other hand, the observed minor differences in genderrelated performance decay could be associated with biological mechanisms; however, they could be equally due to socio-cultural factors given certain social life differences of females and males of all ages and in all cultures.

\section{Conclusion}

In conclusion, taken together, the quantitative analyses of world records of Masters athletes described here suggest that there are no significant differences in the rate of "age-related decline in athletic performance" between females and males. This is unexpected in terms of gender-related sport behaviors. The consequent implications may have long-term influences on the biology, physiopathology, and management of early aging, especially in terms of metabolic sarcopenia, cancer cachexia, aging per se, and its complications [58-69].

\section{References}

1. Barford A, Dorling D, Davey Smith G, Shaw M (2006) Life expectancy: Women now on top everywhere. BMJ 332(7545): 808.

2. Lewis DA, Kamon E, Hodgson JL (1986) Physiological differences between genders: Implications for sports conditioning. Sports Med 3(5): 357-369.

3. Hunter SK, Stevens AA (2013) Sex differences in marathon running with advanced age: Physiology or participation? Med Sci Sports Exerc 45(1): 148-156.

4. Mascherini G, Castizo-Olier J, Irurtia A, Petri C, Galanti G (2018) Differences between the sexes in athletes' body composition and lower limb bioimpedance values. Muscles Ligaments Tendons J 7(4): 573-581.

5. Gava P, Kern H, Carraro U (2015) Age-associated power decline from running, jumping, and throwing male Masters World Records. Exp Aging Res 41(2): 115-135. 
6. Baker AB, Tang YQ, Turner MJ (2003) Percentage decline in masters super athlete track and field performance with aging. Exp Aging Res 29(1): 47-65.

7. Baker AB, Tang YQ. (2010) Aging performance for masters records in athletics, swimming, rowing, cycling, triathlon and weightlifting. Exp Aging Res 36(4): 453-477.

8. Böttiger LE (1973) Regular decline in physical working capacity with age. Br Med J 3(5874): 270-271.

9. Edmunds K, Gíslason M, Sigurðsson S, Guðnason V, Harris T, et al. (2018) Advanced quantitative methods in correlating sarcopenic muscle degeneration with lower extremity function biometrics and comorbidities. PLoS One 13(3): e0193241.

10. Frontera W, Hughes VA, Fielding RA, Fiatarone MA, Evans WJ, et al. (2000) Aging of skeletal muscle: A 12-yr longitudinal study. J Appl Physiol 1985 88(4): 1321-6132.

11. Grassi B, Cerretelli P, Narici MV, Marconi C (1991) Peak anaerobic power in master athletes. Eur J Appl Physiol Occup Physiol 62(6): 394-399.

12. Mitchell WK, Williams J, Atherton P, Lund J, et al. (2012) Sarcopenia, dynapenia, and the impact of advancing age on human skeletal muscle size and strength; a quantitative review. Front Physiol 3: 260.

13. Larsson L, Degens H, Li M, Salviati L, Lee YI, et al. (2019) Sarcopenia: Aging-related loss of muscle mass and function. Physiol Rev 99(1): 427511.

14. Metter EJ, Conwit R, Tobin J, Fozard JL (1997) Age-associated loss of power and strength in the upper extremities in women and men. J Gerontol A Biol Sci Med Sci 52(5): B267-B276.

15. Skelton DA, Greig CA, Davies JM, Young A (1994) Strength, power and related functional ability of healthy people aged 65-89 years. Age Ageing 23(5): 371-377.

16. Young BW, Starkes JL (2005) Career-span analyses of track performance: Longitudinal data present a more optimistic view of age-related performance decline. Exp Aging Res 31(1): 69-90.

17. Runge M, Rittweger J, Russo CR, Schiessl H, Felsenberg D (2004) Is muscle power output a key factor in the age-related decline in physical performance? A comparison of muscle cross section chair-rising test and jumping power. Clin Physiol Funct Imaging 24(6): 335-340.

18. Gava P, Ravara B (2019) Master World Records show minor gender differences of performance decline with aging. Eur J Transl Myol 29(3): 8327.

19. Ravara B, Gava P, Taylor MJ, Pond AL (2019) Statistical analysis of master world records: Surprisingly minor gender differences of aging performance decay. Physiother Res Rep 2: 1-6.

20. Josip Miočić, Korona LZ (2019) Importance of regression analysis in sports information systems at evaluation of sports and sports associations. Res Inves Sports Med. 5(5). RISM.000621.2019. DOI: 10.31031/RISM.2019.05.000621.

21. International Association of Athletics Federation.

\section{World Master Atheltics.}

23. Andrade JM, Estévez-Peréz MG (2014). Statistical comparison of the slopes of two regression lines: A tutorial. An Chim Acta 838: 1-12.

24. Strutz T (2016) Data fitting and uncertainty (A practical introduction to weighted least squares and beyond). Springer Vieweg.

25. Winter EM (2005) Jumping: Power or impulse. Med Sci Sports Exerc 37: 523.

26. Knudson DV (2009) Correcting the use of the term "power" in the strength and conditioning literature. J Strength Cond Res 23(6): 19021908.
27. Samozino P, Rejc E, Di Prampero E, Belli A, Morin JB (2012) Optimal force-velocity profile in balistic movements. Altius: Citius or fortius? Med Sci Sports Exerc 44(2): 313-322.

28. Canavan PK, Vescovi JD (2004) Evaluation of power prediction equations: Peak vertical jumping power in women. Med Sci Sports Exerc 36(9): 1589-1593.

29. Lepers R, Stapley PJ (2016) Master athletes are extending the limits of human endurance. Front Physiol 7: 613.

30. Coast JR, Blevins JS, Wilson BA (2004) Do gender differences in running performance disappear with distance? Can J Appl Physiol 29(2): 139145 .

31. Tezze C, Romanello V, Desbats MA, Fadini GP, Albiero M, et al. (2017) Age-associated loss of OPA1 in muscle impacts muscle mass, metabolic homeostasis, systemic inflammation, and epithelial senescence. Cell Metab 25(6): 1374-1389.

32. Romanello V, Scalabrin M, Albiero M, Blaauw B, Scorrano L, et al. (2019) Inhibition of the fission machinery mitigates OPA1 impairment in adult skeletal muscles. Cells 8(6).

33. Favaro G, Romanello V, Varanita T, Andrea Desbats M, Morbidoni V, et al. (2019) DRP1-mediated mitochondrial shape controls calcium homeostasis and muscle mass. Nat Commun 10(1): 2576.

34. Rodríguez-Nuevo A, Díaz-Ramos A, Noguera E, Díaz-Sáez F, Duran X, et al. (2018) Mitochondrial DNA and TLR9 drive muscle inflammation upon Opa1 deficiency. EMBO J 37(10). pii: e96553.

35. Marroncelli N, Bianchi M, Bertin M, Consalvi S, Saccone V, et al. (2018) HDAC4 regulates satellite cell proliferation and differentiation by targeting P21 and Sharp1 genes. Sci Rep 8(1): 3448.

36. Pigna E, Renzini A, Greco E, Simonazzi E, Fulle S, et al. (2018) HDAC4 preserves skeletal muscle structure following long-term denervation by mediating distinct cellular responses. Skelet Muscle 8(1): 6.

37. Pigna E, Sanna K, Coletti D, Li Z, Parlakian A et al. (2018) Increasing autophagy does not affect neurogenic muscle atrophy. Eur J Transl Myol 28(3): 7687.

38. Renzini A, Benedetti A, Bouchè M, Silvestroni L, Adamo S, et al. (2018) Culture conditions influence satellite cell activation and survival of single myofibers. Eur J Transl Myol 28(2): 7567.

39. Renzini A, Marroncelli N, Noviello C, Moresi V, Adamo S, et al. (2018) HDAC4 regulates skeletal muscle regeneration via soluble factors. Front Physiol 9: 1387.

40. Seaborne RA, Strauss J, Cocks M, Shepherd S, O’Brien TD, et al. (2018) Human skeletal muscle possesses an epigenetic memory of hypertrophy. Sci Rep 8(1): 1898.

41. Pigna E, Berardi E, Aulino P, Rizzuto E, Zampieri S, et al. (2016) Aerobic exercise and pharmacological treatments counteract cachexia by modulating autophagy in colon cancer. Sci Rep 6: 26991.

42. Carraro U, Kern H, Gava P, Zampieri S, Carraro U et al. (2017) Recovery from muscle weakness by exercise and FES: Lessons from Masters, active, or sedentary seniors and SCI patients. Aging Clin Exp Res 29(4): 579-590.

43. Carraro U, Albertin G, Gava P, Ravara B, Piccione F, et al. (2018) Muscle and skin improve by home-based FES and full-body in-bed gym. Biol Eng Med 3(3). doi: 10.15761/BEM.1000S1003.

44. Hofer C, Loefler S, Kern H, Zampieri S, Albertin G, et al. (2018) Two years of FES training improves muscle fibers of thigh muscles in long-term thoracic level-complete spinal cord injury. Biol Eng Med 3(3): 1-5.

45. Barberi L, Scicchitano BM, Musaro A (2015) Molecular and cellular mechanisms of muscle aging and sarcopenia and effects of electrical stimulation in seniors. Eur J Transl Myol 25(4): 231-236. 
46. Cvecka J, Tirpakova V, Sedliak M, Kern H, Mayr W, et al. (2015) Physical activity in elderly. Eur J Transl Myol 25(4): 249-252.

47. Hamar D (2015) Universal linear motor driven leg press dynamometer and concept of serial stretch loading. Eur J Transl Myol 25(4): 215-219.

48. Kern H, Barberi L, Löfler S, Sbardella S, Burggraf S, et al. (2014) Electrical stimulation counteracts muscle decline in seniors. Front Aging Neurosci 6: 189.

49. Mayr W (2015) Neuromuscular electrical stimulation for mobility support of elderly. Eur J Transl Myol 25: 263-238.

50. Mosole S, Carraro U, Kern H, Loefler S, Fruhmann H, et al. (2014) Longterm high-level exercise promotes muscle reinnervation with age. J Neuropathol Exp Neurol 73(4): 284-294.

51. Protasi F (2015) Mitochondria association to calcium release units is controlled by age and muscle activity. Eur J Transl Myol 25(4): 257-262.

52. Sarabon N, Löfler S, Hosszu G, Hofer C (2015) Mobility test protocols for the elderly: A methodological note. Eur J Transl Myol 25(4): 253-256.

53. Zampieri S, Pietrangelo L, Loefler S, Fruhmann H, Vogelauer M, et al. (2015) Lifelong physical exercise delays age-associated skeletal muscle decline. J Gerontol A Biol Sci Med Sci 70(2): 163-173.

54. Zampieri S, Mammucari C, Romanello V, Barberi L, Pietrangelo L, et al. (2016) Physical exercise in aging human skeletal muscle increases mitochondrial calcium uniporter expression levels and affects mitochondria dynamics. Physiol Rep 4(24): e13005.

55. Tanaka H, Seals DR (2008) Endurance exercise performance in masters athletes: Age-associated change and underlying physiological mechanisms. J Physiol 586(1): 55-63.

56. Tanaka H, DeSouza CA, Jones PP, Stevenson ET, Davy KP, et al. (1997) Greater rate of decline in maximal aerobic capacity with age in physically active vs. sedentary healthy women. J Appl Physiol (1985) 83(6): 19471953.

57. Wiswell RA, Hawkins SA, Jaque SV (2001) Relationship between physiological loss, performance decrement, and age in master athletes. J Gerontol A Biol Sci Med Sci 56: M618-M626.
58. Paoli A, Mancin L, Saoncella M, Grigoletto D, Pacelli FQ, et al. (2019) Mind-muscle connection: Effects of verbal instructions on muscle activity during bench press exercise. Eur J Transl Myol 29(2): 8250.

59. Proia P, Amato A, Contrò V, Monaco AL, Brusa J, et al. (2019) Relevance of lactate level detection in migrane and fibromyalgia. Eur J Transl Myol 29(2): 8202.

60. Argilés JM, López-Soriano FJ, Stemmler B, Busquets S (2019) Therapeutic strategies against cancer cachexia. Eur J Transl Myol 29(1): 7960.

61. Gabellini D, Musarò A (2018) Report on abstracts of the $15^{\text {th }}$ meeting of IIM, the Interuniversity Institute of Myology, Assisi, Italy, October 11-14, 2018. Eur J Transl Myol 28(4): 7957.

62. Bouchè M, Lozanoska-Ochser B, Proietti D, Madaro L (2018) Do neurogenic and cancer-induced muscle atrophy follow common or divergent paths? Eur J Transl Myol 28(4): 7931.

63. Sajer S, Guardiero GS, Scicchitano BM (2018) Myokines in home-based functional electrical stimulation-induced recovery of skeletal muscle in elderly and permanent denervation. Eur J Transl Myol 28(4): 7905.

64. Taylor MJ, Fornusek C, Ruys A (2018) The duty cycle in Functional Electrical Stimulation research. Part II: Duty cycle multiplicity and domain reporting. Eur J Transl Myol 28(4): 7733.

65. Taylor MJ, Fornusek C, Ruys AJ (2018) Reporting for duty: The duty cycle in functional Electrical Stimulation research. Part I: Critical commentaries of the literature. Eur J Transl Myol 28(4): 7732.

66. Kiaee SZF, Rahimi B (2018) Investigation of dyspnea using cardiopulmonary exercise test among patients resorting to the respiratory tests. Eur J Transl Myol 28(3): 7556.

67. Damrauer JS, Stadler ME, Acharyya S, Baldwin AS, Couch ME, et al. (2018) Chemotherapy-induced muscle wasting: association with NF- $\kappa B$ and cancer cachexia. Eur J Transl Myol 28(2): 7590.

68. Coletti D (2018) Chemotherapy-induced muscle wasting: an update. Eur J Transl Myol 28(2): 7587.

69. Tehrani KHN, Hajiloo M, Asadollahi E, Lagini FP (2018) Prevalence of muscular dystrophy in patients with muscular disorders in Tehran, Iran. Eur J Transl Myol 28(2): 7380.

For possible submissions Click below: 